40 Aromaa A, Kohonnut verenpaine ja sen kansanterveydellinen merkitys Suomessa. Helsinki : Social Security Institute publications, $1981: 17$.

Vol B2. Helsinki: National Public Health Institute, 1984

42 Hatano S, WHO Collaborative Study Group. Experience from a multicenter stroke register: a preliminary report. Bull WHO 1976;54:540-53.

43 Tuomilehto J, Puska P, Nissinen A, et al. Community-based prevention of hypertension in North Karelia, Finland. Ann Clin Res 1984;16(suppl 38):

44 Pietinen $P$, Tanskanen A, Nissinen A, Tuomilehto J, Puska P. Changes in dietary habits and knowledge concerning salt during a community-based

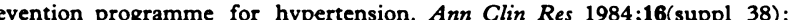
$154-9$.

45 Jalkanen I Tuomilehto J Salonen JT, Nissinen A, Pietinen P, Puska P. Changes in body mass index during a ten year follow-up of the adult general population of East Finland [Abstract]. The IV International Congress on Obesity. New York, USA 1983: October 5-8, Abstract book:40a.

46 Medical Research Council Working Party on Mild to Moderate Hypertension. Randomised controlled trial of treatment for mild hypertension: design and pilot trial. Br Med F 1977; ;:1437-40.

(Accepted 2 fuly 1985)

\title{
Palmoplantar pustulosis and smoking
}

\author{
CONOR J O'DOHERTY, CECILIA MACINTYRE
}

\begin{abstract}
A multicentre case-control study of 216 patients with palmoplantar pustulosis and 626 controls with miscellaneous dermatoses showed a considerably higher prevalence of smoking in the group with palmoplantar pustulosis. This was the first indication that smoking may be an important factor in this skin disease, possibly by affecting the inflammatory responses of the skin.
\end{abstract}

\section{Introduction}

Palmoplantar pustulosis is a chronic condition of unknown cause characterised by sterile yellow pustules that fade into brown macules, lying in areas of erythema and scaling (figure). Although at one time it was thought to be a variant of psoriasis, the current trend is to separate the two conditions. ${ }^{1}$ In Europe it affects women about three times as often as men, ${ }^{2}$ but in Japan the sex ratio of those affected is fairly even. ${ }^{3}$ ' It is recalcitrant to treatment, particularly with topical agents. Responses to systemic agents such as photochemotherapy, ${ }^{b}$ retinoids, $^{\circ}$ and tetracyclines $^{7}$ are temporary, and the condition usually relapses after treatment is stopped. This suggests that the causative factor is still at work and that such treatments are merely suppressive. One of us (CO'D) noted that many patients with palmoplantar pustulosis smoked cigarettes, and a pilot study suggested an association between palmoplantar pustulosis and smoking. ${ }^{8} \mathrm{~A}$ retrospective multicentre case-control survey was therefore undertaken to investigate the prevalence of smoking in patients with palmoplantar pustulosis and in controls.

\section{Patients and methods}

The disease indexes of five departments of dermatology in Edinburgh, London, Cardiff, Manchester, and Airdrie were examined and the names and hospital numbers of all patients presenting with palmoplantar pustulosis since 1980 extracted. Their home address and that of their general practitioner as well as the date of onset of palmoplantar pustulosis and date of first presentation at the skin clinic were recorded from their clinical notes. Each case of palmoplantar pustulosis was then matched for age, sex, and date of presentation with three controls

\footnotetext{
Department of Dermatology and the Medical Computing and Statistics Unit, University of Edinburgh

CONOR J O'DOHERTY, MSC, MRCP, lecturer in dermatology

CECILIA MACINTYRE, BSC, MSC, lecturer in statistics
}

Correspondence to: Dr Conor J O'Doherty, Prince of Wales Hospital, London N15 4AW. with miscellaneous dermatoses. Three suitable controls could not be found for nine cases $(4 \%)$, however, and only two controls were therefore selected, while nine other patients with palmoplantar pustulosis over the age of 60 were each matched with four controls because of the possibility that some selected controls might have died. In total 216 cases and 626 controls were selected from the five centres. Permission to approach their patients was received from the general practitioners of those selected as cases and controls, and the study was approved by the medical ethical committees of the respective centres.

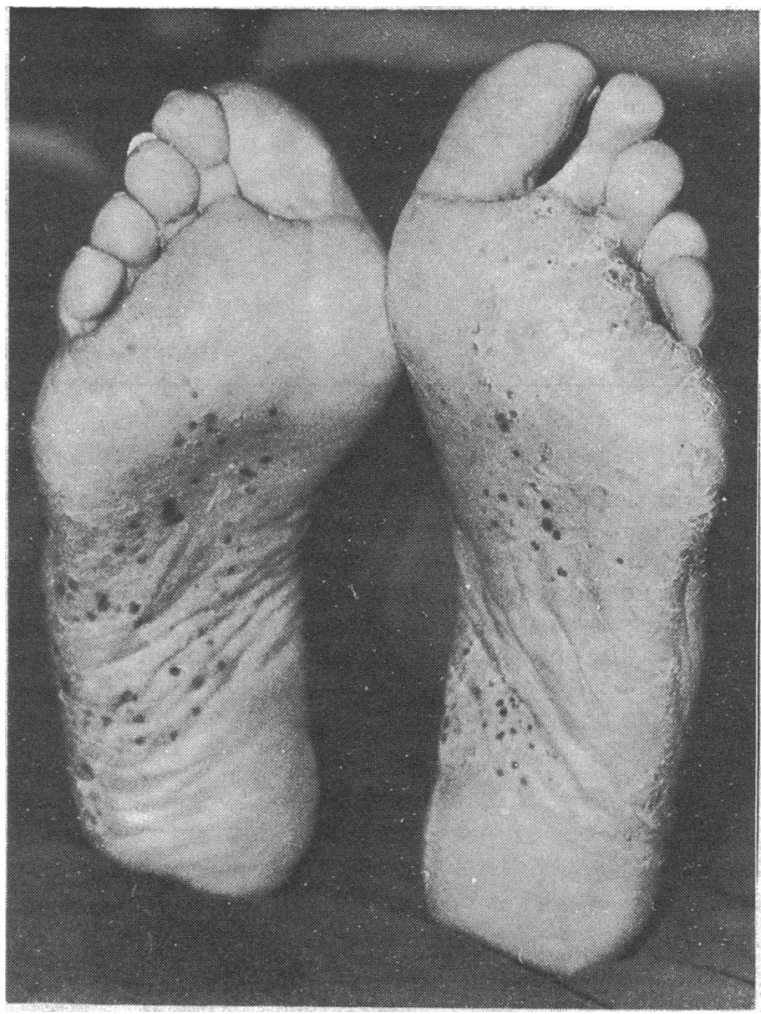

Case of palmoplantar pustulosis.

A letter seeking their cooperation, a stamped addressed envelope, and a questionnaire were sent to all subjects. The questionnaire was designed to ensure that it was possible to deduce from it the smoking habits of the control patients at the time of onset of skin disease in their matched cases. All subjects were asked their occupation to assess social class, and a question on consumption of alcohol was included in the questionnaire for distraction.

For the purpose of this study smokers were arbitrarily defined as people who had ever smoked more than one cigarette a day, one small cigar a day, or one ounce of pipe tobacco a month for longer than a 
year and who were smoking at the time of onset of palmoplantar pustulosis. An ex-smoker was a patient who had smoked for longer than one year but who had not smoked during the year of onset of palmoplantar pustulosis. A patient was considered a non-smoker if he had never smoked at any time in his life up to the time of onset of palmoplantar pustulosis. If no reply had been received after four weeks a second letter was sent with another copy of the questionnaire. If there was still no reply a copy of the questionnaire was sent to the general practitioners of the non-responders. A letter was enclosed seeking their help in collecting data, but, to limit bias, this did not show that smoking habits were the main subject of the study.

Information from the returned questionnaires was placed on predesigned data sheets and stored on computer. The method of analysis was a conditional logistic regression analysis designed for matched data, which allowed for a variable number of matched controls per case. The program used was adopted from one by Breslow and Day. If no information was available on a case the controls corresponding to that case were excluded from the matched analysis. Similarly, a case was discarded if there were no data for any of its matched controls.

\section{Results}

Table I shows the details of the response of the 842 subjects, including the ratio of women to men, and the mean age at presentation of the responders. General practitioners refused permission to contact one patient with palmoplantar pustulosis and three controls. Two

TABLE I-Details of cases and controls in study

\begin{tabular}{lcc}
\hline & $\begin{array}{c}\text { Patients with } \\
\text { palmoplantar pustulosis }\end{array}$ & Controls \\
\hline Total No selected & 216 & 626 \\
Permission refused by: & 1 & 3 \\
General practitioner & 2 & 2 \\
Patient & 21 & 8 \\
Dead & 12 & 75 \\
"Gone away" & 180 & 51 \\
No reply & 144 & 487 \\
Responders & 36 & 392 \\
Women & $4: 1$ & 95 \\
Men & $51 \cdot 0$ & $4: 1$ \\
Sex ratio & $(19-78)$ & $51 \cdot 4$ \\
Mean age at presentation (and range) (years) & & $(20-80)$ \\
\hline
\end{tabular}

patients with palmoplantar pustulosis and two control patients returned their questionnaire expressing a wish not to participate. Envelopes for 21 cases and 75 controls were returned as "gone away" and not at their registered addresses. No reply was received from 12 patients with palmoplantar pustulosis and 51 controls, and eight controls had died. Thus out of the initial 216 patients with palmoplantar pustulosis matched with 626 controls, 180 patients and 487 controls replied with data that could be evaluated. There were 177 matched sets, and three cases were discarded owing to lack of response from their selected controls.

\section{Smoking habits in cases and controls}

Using the detailed answers to the questionnaire we determined whether 485 controls were smokers at the time of onset of palmoplantar pustulosis in their matched case: $144(80 \%)$ of the group with palmoplantar pustulosis were smokers at that time compared with $175(36 \%)$ controls (table II). From the conditional logistic regression analysis the estimated relative risk of smokers contracting the disease was $7 \cdot 2$

TABLE II-Smoking habits of cases $(n=180)$ and controls $(n=485)^{*}$

\begin{tabular}{|c|c|c|}
\hline & $\begin{array}{l}\text { No }\left(\begin{array}{l}0 \\
0\end{array}\right) \text { of patients with } \\
\text { palmoplantar pustulosis }\end{array}$ & No $(\%)$ of controls \\
\hline $\begin{array}{l}\text { Never smoked } \\
\text { Ex-smoker at onset of disease } \\
\text { Smoker at onset of disease }\end{array}$ & $\begin{array}{c}16(9) \\
20(11) \\
144(80)\end{array}$ & $\begin{array}{l}224(46) \\
86(18) \\
175^{*}(36)\end{array}$ \\
\hline
\end{tabular}

-Smoking habits of two controls could not be determined.
( $p<0.00001)$. The $99 \%$ confidence limits around this estimate were $3 \cdot 9-13 \cdot 2$. Only $4(2 \cdot 2 \%)$ cases and $26(5 \cdot 3 \%)$ controls had ever smoked a pipe, and $3(1.7 \%)$ cases and $9(1.8 \%)$ controls had smoked cigars. The estimated relative risk did not change appreciably when cigarette smoking alone was considered. Similarly, there was no difference in the relative risk for men and women who smoked when this was analysed separately. Table III gives the distribution of smoking habits for these two groups, taking into account this matching, and shows a significantly higher prevalence of smoking in the group with palmoplantar pustulosis. The relative risk of smoking was calculated for each centre separately. There was a significant risk of smoking in each one at the $5 \%$ level, and when tested against the relative risk estimate of $7 \cdot 2$ for the pooled data no evidence of any difference was discovered $\left(\chi^{2}=6 \cdot 3, d f=4\right)$.

TABLE III-Analysis of smoking habits of 177 matched sets

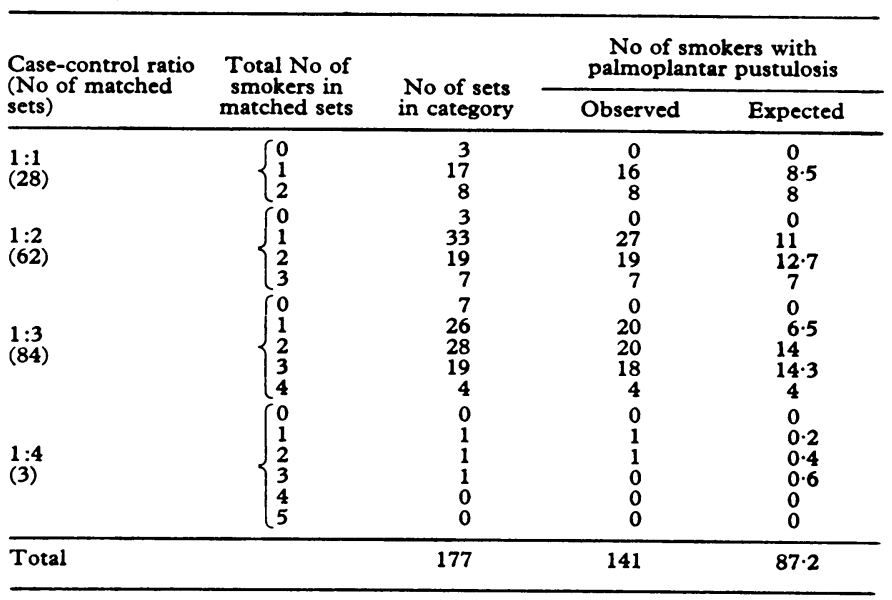

\section{Smoking and social class}

Patients could not be matched for social class at first, but the assessment was important as smoking is dependent on social class. Patients were therefore asked about their jobs and those of their spouses or parents. Many answered this question as housewife, unemployed, or retired so that data on social class as determined by the Registrar General's classification was available for only 601 patients, ${ }^{10}$ resulting in 157 case-control matched sets. The controls tended to be of a lower social class than the group with palmoplantar pustulosis (table IV). The data were analysed incorporating social class as a possible confounding factor, and this slight imbalance of social class resulted in a higher estimate of relative risk of 9.0 ( $99 \%$ confidence interval 4.4-18.4). Analysis of smoking alone, therefore, had given a conservative estimate of risk.

TABLE IV-Distribution of social class in two groups

\begin{tabular}{lcc}
\hline Social class & No $(\%)$ of cases & No (\%) of controls \\
\hline 1 & $4(2)$ & $14(3)$ \\
2 & $23(13)$ & $60(12)$ \\
3 & $52(29)$ & $120(25)$ \\
4 & $66(37)$ & $136(28)$ \\
5 & $19(11)$ & $106(22)$ \\
Unclassified & $16(9)$ & $51(10)$ \\
\hline Total & $180(100)$ & $487(100)$ \\
\hline
\end{tabular}

\section{Non-responders}

A minor difference was found between the prevalences of response of the patients with palmoplantar pustulosis $(83 \%)$ and controls (78\%), and in comparing the proportions of smokers who replied to the questionnaire immediately with those who needed reminders we found that smokers were generally slower in responding. This could have resulted in a bias due to a lower prevalence of response among controls. Even when the non-responding controls were considered as smokers and the data reanalysed, however, the relative risk was estimated as $5 \cdot 4(99 \%$ confidence limits $3 \cdot 1-9 \cdot 6, \mathrm{p}<0 \cdot 00001)$. 
Smoking habits in cases, controls, and population of the United Kingdom

The prevalence of smoking in cases and controls was compared with that of the population of the United Kingdom, gleaned from the General Household Survey, ${ }^{11}$ in which smoking statistics are available only for the decade 1972-82. Thus in this comparison we used cases who got palmoplantar pustulosis after 1971, which included $91 \%$ of the group. The expected number of smokers, given the age and sex distribution, was $65 \cdot 1$ with a variance of $38 \cdot 0$, and the observed number was $132(p<0.00001)$. This shows a significantly higher prevalence of smokers in the group with palmoplantar pustulosis than in the normal population.

As we did not know the year of onset of the dermatoses in the control group we could not estimate whether this group was atypical in its smoking habits at that time. Nevertheless, the current smoking habits of the controls were compared with those of the normal population. The expected number of current smokers among the controls, given the age and sex distribution, was $164 \cdot 7$ with a variance of $106 \cdot 2$. The actual number of smokers observed was 170 (NS). The controls were therefore typical of the national population in terms of prevalence of smoking.

\section{Consumption of alcohol}

Patients were asked whether or not they had consumed, in their adult life, more than one glass of beer, wine, or spirits a week on average. An equal number from each group, $95(52 \cdot 8 \%)$ cases compared with $259(53.4 \%)$ controls, replied in the affirmative (NS).

\section{Smoking and persistence of palmoplantar pustulosis}

Only 16 of the 144 who smoked at the onset of palmoplantar pustulosis had stopped smoking at the time of the survey. No noticeable difference existed between this small group of 16 and those who continued to smoke in terms of persistence of palmoplantar pustulosis.

\section{Discussion}

The sex ratio of 4:1 in favour of women and the mean age at presentation of 51 years are comparable with other European studies of palmoplantar pustulosis. The rate of response to our questionnaire was reasonable considering that our patients were elderly and not attending routine follow up. We have confirmed a high prevalence of smoking in patients with palmoplantar pustulosis in the United Kingdom. The relative risk of palmoplantar pustulosis occurring in smokers as compared with non-smokers is $7 \cdot 2$, and this estimate may be conservative as the slight difference in social class between cases and controls created a bias against the hypothesis.

Although the association between palmoplantar pustulosis and smoking has now been firmly established, the way in which smoking affects the pathogenesis of the disease is unclear. The link may be an indirect one via a mutual association with one or more unknown factors, such as personality or stress, and the fact that almost $10 \%$ of our cases had never smoked shows that smoking does not contribute to the disease in all cases, unless passive smoking can be implicated by further studies. Stopping smoking did not appear to lead to a permanent cure of palmoplantar pustulosis in the 16 cases who had stopped.Two of our own patients succeeded in stopping smoking and improved clinically after six and eight months' follow up, but it is difficult to read anything into these facts as the numbers are small. Smoking invariably began before the onset of the disease so that the disease could not have led to the habit. Thus research directed at finding the aetiological role of smoking in palmoplantar pustulosis may be worth while. No dermatoses have previously been linked with smoking, with the exception of nicotine staining, and the effect of smoking on the skin has not yet been properly evaluated. Indirect evidence for an aetiological role may be adduced from the prevalence of cigarette smoking in both sexes and the sex ratio of the disease in the other populations.
Although the sex ratio of $4: 1$ in favour of women was similar to that of other published European studies, ${ }^{2}{ }^{7}$ this differed from those seen in studies of Japanese patients, when the sex ratio was roughly even. ${ }^{34}$ If smoking is an important aetiological factor then the sex ratio of the disease in various populations should be predictable by a simple calculation. In the United Kingdom, where $43 \%$ of men and $37 \%$ of women smoked in 1980 , the number of affected women would be proportional to the number of women who smoke, multiplied by the relative risk of smoking, plus the proportion of women who do not smoke, all multiplied by the relative risk for women. The number of affected men would be proportional to the number of men who smoke, multiplied by the relative risk for smokers, plus the proportion of men who do not smoke. Thus with the above smoking figures for men and women and the observed relative risk for smokers of $7 \cdot 2$ we find that the ratio of women to men would be: $(63+37 \times 7 \cdot 2)$ $\times R:(57+43 \times 3 \cdot 2)$, where $R$ denotes the relative risk of palmoplantar pustulosis in women compared with men. From our observed sex ratio of $4: 1, R$ is thus estimated as 4.5. Applying these figures to Japan, where $70 \%$ of men and $14 \%$ of women smoked in 1980, we can predict the ratio of women to men to be: $(86+14 \times 7 \cdot 2) \times 4 \cdot 5:(30+70 \times 7 \cdot 2)$, which equals $1 \cdot 6: 1$. If the error of sampling of our estimate of relative risk of smoking on the incidence of palmoplantar pustulosis is considered, this is similar to the published sex ratio of palmoplantar pustulosis in Japan.

Smoking may thus turn out to be important in the aetiology of palmoplantar pustulosis. Smoking is common, however, and the disease itself is relatively rare, so it is probably not the only causative factor, and clearly women are especially predisposed. Smoking could simply be uncovering an inherent abnormality that is particularly associated with women. The disease is characterised histologically by the presence of a pustule full of polymorphonuclear leucocytes tucked underneath the stratum corneum. A leucotactic factor has been isolated from the stratum corneum of patients with palmoplantar pustulosis, ${ }^{12}$ and it is tempting to speculate that smoking may cause its release. Those who develop palmoplantar pustulosis may have an abnormal response to this stimulus-that is, a failure of inhibition or regulation of cutaneous chemotaxis-which leads to a persistent migration of polymorphs towards a specific target.

Many drugs that help the disease interfere with chemotaxis, including tetracyclines, ${ }^{13}$ retinoids, ${ }^{14}$ and benoxaprofen. ${ }^{15}$ This latter drug, no longer available, was effective in palmoplantar pustulosis ${ }^{16}$ and considered to be an inhibitor of the lipoxygenase pathway of the transformation of arachidonic acid, ${ }^{17}$ one product of which is leucotriene $B_{4}$, a potent neutrophil chemoattractant. Thus this pathway may be central to the pathogenesis of this disease, and smoking may affect its apparent and persistent overactivity in palmoplantar pustulosis. The effect of smoking on arachidonic acid metabolism in human keratinocytes, however, has not so far been investigated.

The purpose of this study was to investigate the clinical observation that palmoplantar pustulosis is a disorder associated with smoking. Further investigations into the mechanism of the association are continuing. It is possible that smoking may also affect the pathogenesis of other more common inflammatory dermatoses such as chronic hand dermatitis and psoriasis, which is thought by many to be closely related to palmoplantar pustulosis. Investigations of the link between smoking and palmoplantar pustulosis may increase our insight into these disorders and lead to a better outlook for patients with them.

We thank Dr Michael Jacobson of the Institute of Occupational Medicine for his advice on the composition of the questionnaire; Dr Strachan of ASH for the prevalence figures of smoking in the United Kingdom and Japan; Dr Robin Prescott for his advice on the statistical analysis and mathematical prediction of the Japanese sex ratio in incidence; and the dermatology and records departments of the Royal Infirmary, Edinburgh, the Institute of Dermatology, London, the Skin Hospital, Manchester, the University of Wales College of Medicine, and Monklands District General Hospital, Airdrie, for giving us access to their clinical notes. The survey was made possible 
by the generous support of the Scottish Hospital Endowments Research Trust and would have certainly failed were it not for the dedicated assistance of our secretary, Mrs Jenny Stewart.

\section{References}

1 Baker H, Wilkinson D. Psoriasis. In: Rook A, Wilkinson D, Ebling F, eds. Textbook of dermatology. 3rd ed. Oxford: Blackwell Scientific Publications, 1979:

2 Enfors $W$, Molin L. Pustulosis palmaris et plantaris. A follow up study of a ten year material. Acta Derm Venereol (Stockh) 1971;51:289-94

3 Uehera W. Pustulosis palmaris et plantaris. A review of clinical features and aggravating factors. Acta Otolaryngol [Suppl] (Stockh) 1983;Suppl 401:7-11. Ono T, Jono M, Kito M, et al. Evaluation of tonsillectomy as a treatment for
pustulosis palmaris et plantaris. Acta Otolaryngol [Suppl] (Stockh) 1983;Suppl
401:12-5.

5 Murray D, Corbett M, Warin A. A controlled trial of photochemotherapy for persistent palmoplantar pustulosis. Br f Dermatol 1980;102:659-63.

6 Fredericksson T, Pettersson V. Oral treatment of pustulosis palmo plantaris with a new retinoid, RO 10-9359. Dermatologica 1979;158:60-4.

Ward J, Corbett M, Hanna $M$. A double blind trial of clomocycline in the treatment of persistent palmoplantar pustulosis. Br $\mathcal{F}$ Dermatol 1976;95:317-22.
8 O'Doherty C. The prevalence of cigarette smoking in patients with palmo-plantar pustulosis. Scott Med f $1984 ; 29: 54$

9 Breslow NE, Day NE. Statistical methods in cancer research. Vol 1. Lyons: IARC Scientific Publications, 1980:297-302

10 Office of Population Censuses and Surveys. Classification of occupations. London:

11 Office of Population Censuses and Surveys. General Household Survey 1982.

12 Tagami H, Ofugi S. A leukotactic factor in the stratum corneum of pustulosis palmaris et plantaris A possible mechanism for the formation of the pustule. Acta Derm Venereol (Stockh) 1978;58:401-5.

13 Elewski B, Lamb B, Sams WM, Gammon WR. In vivo suppression of neutrophil chemotaxis by systemically and topically administered tetracycline. $\mathcal{F} \mathrm{Am} \mathrm{Acad}$

Dermatol $1983 ; 8: 807-12$.
14 Orfanos C, Bauer R. Evidence for anti-inflammatory activities of oral synthetic retinoids: experimental findings and clinical experience. $\operatorname{Br} \mathcal{F}$ Dermatol 1983; 109(suppl 25):55-60.

15 Meacock S, Kitchen E, Dawson W. Effects of Benoxaprofen and other nonsteroidal anti-inflammatory drugs on leukocyte migration. Eur 7 Rheumato Inflamm 1979;3:23-8.

16 Fenton D, English J, Wilkinson J. A controlled trial using a lipoxygenase inhibitor We treatment of persistent palmoplantar pustulosis. $\mathrm{Br} \mathcal{F}$ Dermatol 1983;109(suppl 24):25-6.

17 Dawson W, Boot JR, Harvey J, Walker JR. The pharmacology of benoxaprofen with particular reference to effects on lipoxygenase produce formation. Eur $\mathcal{F}$ Rheumatol Inflamm 1982;5:61-8.

(Accepted 20 fune 1985)

\section{SHORT REPORTS}

\section{Nabilone and prochlorperazine: a useful combination for emesis induced by cytotoxic drugs}

The control of emesis induced by cytotoxic drugs remains a major challenge. Our recent experience indicates that the failure rate is high even when patients receive parenteral antiemetic prophylaxis. ${ }^{1}$ Further innovation is clearly required, including the development of antiemetic protocols suitable for outpatient use, as chemotherapy without cisplatin is usually administered on an outpatient basis. Nabilone is a synthetic cannabinoid with established antiemetic activity when administered orally, but adverse effects on the central nervous system, such as dysphoria, have limited its widespread application. ${ }^{2}$ In clinical studies the phenothiazines reduced the incidence of euphoria associated with delta-9-tetrahydrocannabinol, ${ }^{3}$, the most active constituent of cannabis. The aim of this study was to investigate whether such an effect occurred when prochlorperazine was added to nabilone.

\section{Patients, methods, and results}

Thirty four patients (20 women, 14 men; mean age 55 (range 39-76)) entered the study. Four had received previous chemotherapy and had been refractory to other antiemetics, but the remaining 30 were receiving their first course of chemotherapy. None had been given nabilone, and to our knowledge none had taken cannabis in the past. All were receiving cytotoxic regimens without cisplatin. Patients were randomly assigned using a double blind crossover method to nabilone $2 \times 1 \mathrm{mg}$ capsules combined with prochlorperazine $(5 \mathrm{mg})$ or nabilone and placebo. The first dose was given at $10 \mathrm{pm}$ the night before chemotherapy, and three further doses were given at intervals of 12 hours, although if vomiting did not occur the final dose was omitted. Nausea, vomiting, adverse effects, blood pressure, and pulse were recorded on an inpatient basis for the 24 hours after chemotherapy, and patients assessed control of emesis on a linear analogue scale. Wilcoxon's matched pairs signed ranks test was used to compare these variables and the binomial test to analyse patient preference (if any) for either antiemetic.

Four patients did not complete two courses: three died, and chemotherapy was stopped in one. The table shows the results for all 34 patients. Among the patients who completed the crossover there were no significant differences in nausea, vomiting, appetite, assessment on the linear analogue scale, or adverse effects other than those on the central nervous system, which were significantly less common with the combination $(p<0.01)$. A significant number of patients preferred the combination $(15 v 1, \mathrm{p}<0.001) ; 14 \mathrm{had}$ no preference. There was no significant relation between the order of administration of the drug and drug preference (Fisher's exact test).

\section{Comment}

Nabilone alone, or in combination with prochlorperazine, proved to be a highly effective antiemetic, providing complete control of emesis in a large proportion of our patients receiving cytotoxic regimens of considerable emetogenic potential. ${ }^{5}$ Simultaneous administration of the phenothiazine significantly reduced the incidence of adverse effects on the central nervous system related to nabilone, and the patients clearly preferred the combination. Experience with delta-9-tetrahydrocannabinol indicated that the best antiemetic effect was observed in patients developing "highs." Therefore, in this study the trend towards better control of emesis with the combination of antiemetics was reassuring, as we were concerned that if prochlorpera-

Nausea, vomiting, appetite, and side effects after chemotherapy in all patients. (Figures are numbers $(\%)$ of patients)

\begin{tabular}{|c|c|c|}
\hline & $\begin{array}{c}\text { Nabilone } \\
(n=31)\end{array}$ & $\begin{array}{c}\text { Nabilone and } \\
\text { prochlorperazine } \\
(\mathbf{n}=33)\end{array}$ \\
\hline $\begin{array}{l}\text { Episodes of vomiting: } \\
\text { None } \\
1-2 \\
>2\end{array}$ & $\begin{array}{r}23(74) \\
6(19) \\
2(7)\end{array}$ & $\begin{array}{rr}28 & (85) \\
2 & (6) \\
3 & (9)\end{array}$ \\
\hline $\begin{array}{l}\text { Duration of vomiting (hours): } \\
\text { None } \\
1-4 \\
\mathbf{4 - 8}\end{array}$ & $\begin{array}{r}23(74) \\
5(16) \\
3(10)\end{array}$ & $\begin{array}{r}28(85) \\
4(12) \\
1(3)\end{array}$ \\
\hline $\begin{array}{l}\text { Severity of nausea: } \\
\text { None } \\
\text { Mild } \\
\text { Moderate } \\
\text { Severe }\end{array}$ & $\begin{array}{r}23(74) \\
6(19) \\
2(7)\end{array}$ & $\begin{array}{r}29(88) \\
4(12)\end{array}$ \\
\hline $\begin{array}{l}\text { Duration of nausea (hours): } \\
\text { None } \\
1-4 \\
4-8 \\
>8\end{array}$ & $\begin{array}{r}23(74) \\
4(13) \\
1(3) \\
3(10)\end{array}$ & $\begin{aligned} 27 & (88) \\
3 & (9) \\
1 & (3)\end{aligned}$ \\
\hline $\begin{array}{l}\text { Appetite: } \\
\text { Normal } \\
\text { Decreased }\end{array}$ & $\begin{array}{l}19(61) \\
12(39)\end{array}$ & $\begin{array}{l}23(70) \\
10(30)\end{array}$ \\
\hline $\begin{array}{l}\text { Sedation: } \\
\text { None } \\
\text { Mild } \\
\text { Moderate } \\
\text { Severe }\end{array}$ & $\begin{array}{r}4(13) \\
15(48) \\
9(29) \\
3(10)\end{array}$ & $\begin{aligned} 3(9) \\
17(52) \\
10(30) \\
3(9)\end{aligned}$ \\
\hline $\begin{array}{l}\text { Dizziness: } \\
\text { None } \\
\text { Mild } \\
\text { Moderate } \\
\text { Severe }\end{array}$ & $\begin{array}{l}12(39) \\
15(48) \\
1(3) \\
3(10)\end{array}$ & $\begin{array}{l}14(42) \\
13(39) \\
5(16) \\
1(3)\end{array}$ \\
\hline $\begin{array}{l}\text { Dry mouth: } \\
\text { None } \\
\text { Mild } \\
\text { Moderate } \\
\text { Severe }\end{array}$ & $\begin{array}{l}6(19) \\
11(36) \\
9(29) \\
5(16)\end{array}$ & $\begin{array}{r}4(12) \\
10(30) \\
14(42) \\
5(16)\end{array}$ \\
\hline Postural hypotension & $2(7)$ & $1(3)$ \\
\hline $\begin{array}{l}\text { Adverse effects on central nervous system: } \\
\text { Visual hallucinations } \\
\text { Euphoria } \\
\text { Dysphoria } \\
\text { Disorientation }\end{array}$ & $\begin{array}{l}4(13) \\
2^{*}(7) \\
7(23) \\
1 \dagger(3)\end{array}$ & $\begin{array}{ll}1 & (3) \\
1 & (3)\end{array}$ \\
\hline
\end{tabular}

*Both had hallucinations.

†Also dysphoria. 